\title{
Bullous Aplasia Cutis Congenita-Description of a Novel Dermoscopic Feature
}

\author{
Aradhana Rout ${ }^{1}$, Sandeep Arora ${ }^{1}$, Rajeshwari Dabas ${ }^{1}$, Debatraya Paul ${ }^{1}$
}

1 Department of Dermatology, Command Hospital Air Force Bangalore, India

Key words: bullous aplasia cutis congenita, cobblestone pattern, developmental abnormality, congenital anomalies, dermoscopy

Citation: Rout A, Arora S, Dabas R, Paul D. Bullous aplasia cutis congenita-description of a novel dermoscopic feature. Dermatol Pract Concept. 2021;11(2):e2021012. DOI: https://doi.org/10.5826/dpc.1102a12

Accepted: July 30, 2020; Published: March 8, 2021

Copyright: $@ 2021$ Rout et al. This is an open-access article distributed under the terms of the Creative Commons Attribution License BYNC-4.0, which permits unrestricted noncommercial use, distribution, and reproduction in any medium, provided the original author and source are credited.

Funding: None.

Competing interests: The authors have no conflicts of interest to disclose.

Authorship: All authors have contributed significantly to this publication.

Corresponding author: Sandeep Arora, MD, Department of Dermatology, Command Hospital Air Force, Bangalore 560007, India. Email: aroraderma@gmail.com

\section{Case Presentation}

A 1-year-old boy presented with a solitary alopecic atrophic area on the scalp and a history of a fluid-filled lesion at the site that had presented a few days after birth and healed with thinning of skin (Figure 1A). Examination revealed a $2 \times 2 \mathrm{~cm}$ solitary, well-defined alopecic patch with atrophy on the scalp vertex without any underlying bone defect.

Dermoscopy revealed (Figure 1B) absent follicular openings, a few distended blood vessels, a few visible hair bulbs, and a branching network of reticulated white-colored streaks on atrophic skin resembling cobblestones.
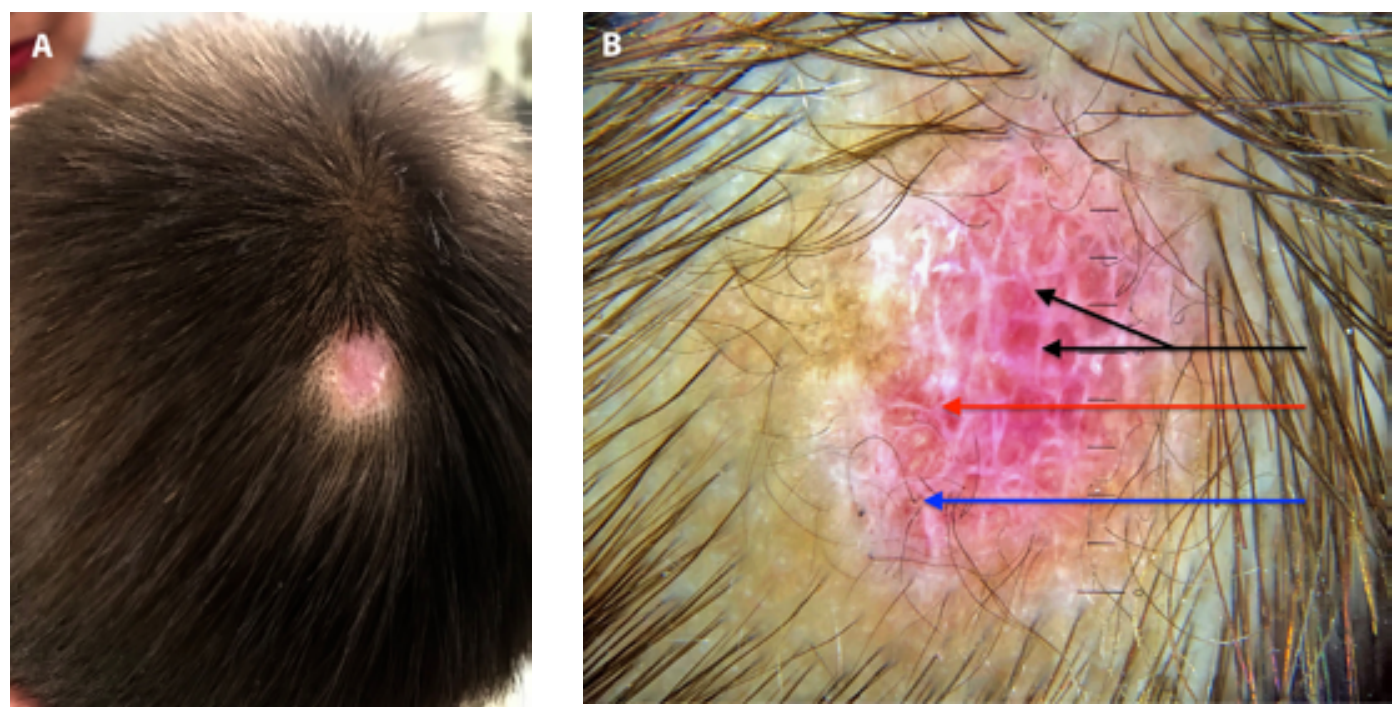

Figure 1. (A) Solitary alopecic patch with atrophic translucent skin and the (B) dermoscopic image with absent follicular openings, a few distended blood vessels (red arrow), a few visible pigmented hair bulbs (blue arrow), and cobblestoning (black arrows). 


\section{Teaching Point}

Although all signs may not be present in a case, the classic dermoscopic findings described are [1]: absence of follicular openings, thick, distended blood vessels, a hair collar sign with hair shafts arranged radially and forming a ring of hypertrichosis, and bulbs of anagen hair seen through the translucent epidermis resembling a golf stick [2]. However, recently a new pseudomembranous pattern has been identified, which can be included within a clinical and dermoscopic spectrum ranging from the classic to the pure membranous form of aplasia cutis congenita [3]. Of these findings, our case had only a few distended vessels but was absent hair collar and golf stick signs. However, the atrophic skin in our case presented as cobblestoning visible on dermoscopy, which is a unique feature of bullous aplasia cutis congenita.

\section{References}

1. Costa Pinheiro AM, Silva Mauad EB, Amarante Fernandes LF, Bruno Drumond R. Aplasia cutis congenita: trichoscopy findings. Int J Trichology. 2016;8(4):184-185. DOI: 10.4103/ijt.ijt_90_15. PMID: 28442877.

2. Cutrone M, Grimalt R. The trichoscopic "golf club set" sign for bullous aplasia cutis congenita. Skin Appendage Disord. 2018;4(4):320322. DOI: 10.1159/000486463. PMID: 30410906.

3. Chessa MA, Filippi F, Patrizi A, et al. Aplasia cutis: clinical, dermoscopic findings and management in 45 children. $J$ Eur Acad Dermatol Venereol.2020;34(11):e724-e726. DOI: 10.1111/ jdv.16542. doi:10.1111/jdv.16542. PMID: 32346876. 